\title{
El deber de información en el seguro como instrumento de decisión racional en la contratación y de tutela a favor del asegurado*
}

\section{Roberto Ríos Ossa**}

RESUmen. Tanto la doctrina como los ordenamientos jurídicos se han ocupado de la problemática de la información en los contratos y, bajo este estado de la cuestión, surge el deber de información como un instrumento que permitiría morigerar el desequilibrio negocial. En el caso del seguro, especialmente en su modalidad de contrato estandarizado y de adhesión, además de su contenido altamente técnico y de difícil comprensión, el deber de información debe cumplir una función destinada a la mejor comprensión posible del contenido contractual, muy especialmente, de la forma como queda protegido el asegurado.

PALABRAS ClAVE: información, asimetría, seguros.

* Fecha de recepción: 27 de octubre de 2019. Fecha de aceptación: 27 de abril de 2020.

Para citar el artículo: Ríos Ossa, R., "El deber de información en el seguro como instrumento de decisión racional en la contratación y de tutela a favor del asegurado", Revista de Derecho Privado, n. ${ }^{\circ}$ 39, julio-diciembre 2020, 203-231, DoI: https://doi.org/10.18601/01234366.n39.09.

Este trabajo se inscribe dentro del proyecto de investigación Fondecyt n. ${ }^{\circ}$ 11180263, titulado "Las fronteras de los deberes de conducta en el régimen legal de seguros en relación con los efectos derivados de su incumplimiento: los efectos de la conservación y la rescisión del contrato de seguro y la indemnización por daños y perjuicios, por el incumplimiento de los deberes de información y asesoramiento del asegurador y los intermediarios", en el que el autor de este trabajo es el investigador responsable.

** Pontificia Universidad Católica de Chile, Santiago de Chile, Chile; profesor de derecho comercial. Doctor en Derecho Privado, Pontificia Universidad Católica de Chile, Santiago de Chile, Chile. Contacto: rrioso@uc.cl. Orcid: 0000-0002-0624-9689. 


\title{
The Duty of Information in the Insurance, as an Instrument of Rational Decision in the Contracting and Protection in Favor of the Insured
}

\begin{abstract}
Both doctrine and legal systems have dealt with the problem of information in contracts and, under this situation, the duty to provide information arises as an instrument that would allow the business imbalance to be reduced. In the case of insurance, especially in its form of a state contract and of adhesion, in addition to its highly technical content, which is difficult to understand, the duty of information must fulfill a function aimed at the best possible understanding of the contractual content, especially as the insured is protected.
\end{abstract}

KEYWORDS: information, asymmetry, insurance.

SumaRIO: Introducción. I. Una visión panorámica del deber de información en el seguro. II. El deber de información como instrumento de tutela a favor del asegurado en su sentido omnicomprensivo. Conclusiones. Referencias.

\section{Introducción}

La problemática sobre la información y la decisión racional y libre de los individuos tiene un nuevo punto de partida en el pensamiento de Simon, en concreto su análisis sobre los modelos de decisión racional (Olympian model, behavioral model of bounded racionalty, intuitive rationality) ${ }^{1}$, disquisición que derivará, entre otras posiciones y factores, en la idea de considerar como lo sustancial no la información en una dimensión cuantitativa -cuánto informar- sino cualitativa -cómo informar- de manera que su receptor pueda comprender la información transmitida y recibida y, con base en ella, discernir racionalmente. Lo anterior quedaría plasmado en el caso del seguro y, en concreto, en nuestra propuesta sobre la existencia de un deber de información -de conducta- omnicomprensivo, pues, la entrega y posterior recepción de información sobre el contenido del contrato es insuficiente y debe ser complementada con la asesoría o ilustración sobre tal contenido, permitiendo, finalmente, una adecuada comprensión sobre los términos del contrato ${ }^{2}$.

1 Simon H. A., Reason in Human Affair, California, Stanford University, 1983, 12 ss. En términos generales, Simon plantea que en toda decisión racional o elección hubo un proceso, previo juicio o, a lo menos, un juicio subyacente en la elección adoptada. Simon, Reason in..., cit., 37. Desde la perspectiva de la teoría económica clásica, Sánchez Santos sostiene que "los individuos deciden teniendo en cuenta la relación entre los beneficios esperados y los costes de las distintas pólizas. Actuando de este modo, con sus elecciones los consumidores estarían maximizando su utilidad esperada (bienestar)". SÁNChEZ SANTOS, J. M., "El mercado de la distribución de seguros en España: bases para al análisis económico de su regulación", en Bataller, J. y Quintáns, M. R. (dirs.), Distribución de seguros privados, Madrid, Marcial Pons, 2019, 21. 
Para nosotros, la dimensión cuantitativa del deber de información apunta en primer término a resolver problemas de déficit de información, supuesto que por lo general los sistemas jurídicos han resuelto dando lugar paradojalmente a la problemática de la sobreabundancia de datos ${ }^{3}$. En segundo lugar, entonces, la dimensión cuantitativa apunta a criterios de proporcionalidad entre el suministro de datos ${ }^{4}$, el tipo contractual en concreto y el mayor o menor grado de ignorancia del receptor. En este contexto, viene la pregunta sobre cómo informar.

En el sentido que hemos apuntado, la formulación sobre cómo resolver los problemas de desigualdad en la contratación ha sido presentada en la doctrina chilena por De la Maza en el ámbito de los deberes de información, la formación del contrato y las problemáticas que conlleva la asimetría informativa ${ }^{5}$, al sostener "que una percepción más agudizada acerca del por qué proteger a los consumidores debería contribuir a agudizar nuestra comprensión acerca de cómo hacerlo"6. Nuestra propuesta tiene como punto de partida lo formulado por el citado autor. No obstante ello, en nuestra opinión y, para el caso concreto del seguro, el deber de información debe ir más allá del mero suministro de datos (dimensión cuantitativa), complementándolo desde una dimensión cualitativa ${ }^{7}$. El cómo resolver el desequilibrio contractual que

2 Se trata de encontrar los mecanismos correctivos de la racionalidad limitada, provocada, entre otros fenómenos, por la asimetría de información. Véase DE LA MAZA, I., "El suministro de información como técnica de protección de los consumidores: los deberes precontractuales de información", Revista de Derecho Universidad Católica del Norte, año 17, n. 2, 2010, 27.

3 En el caso del contrato de seguro, en opinión de Pirilli a la problemática del exceso de información debe considerarse, además, su carácter técnico y la ignorancia del asegurado en esta perspectiva, supuestos que provocan un aumento de la asimetría informativa. PiriLli, D., "La fase precontrattuale nell' assicurazione", Assicurazioni, Rivista de Diritto, Economia e Finanza delle Assicurazzioni private, n. ${ }^{\circ}$ 3., 2013, 429. En el mismo sentido, véase Quintáns, M. R., "Información y conflicto de intereses en la comercialización de seguros", en Girgado, P. (dir.), El contrato de seguro y su distribución en la encrucijada, Pamplona, Aranzadi, 2018, p.219; NASSER, M., Seguros de Personas, Santiago, Thomson-Reuters, 2014, 108.

4 Véase Peñas Moyano, M. J., "Relaciones entre la normativa contractual y de supervisión para la protección del asegurado: El deber de información previa al tomador del seguro", en CUÑAT, V. y BATAller, J. (dirs.), Supervisión de seguros privados, hacia solvencia II, Valencia, Tirant lo Blanch, 2013, 678. Por su parte, De la Maza plantea el problema de la proporcionalidad desde la perspectiva de la sobrecarga de información. DE LA MAZA, I., Los límites del deber precontractual de información, Pamplona, Aranzadi, 2010, 144 ss.

5 Sobre la asimetría como justificante de los deberes de información véanse Monsalve, V., "Consideraciones actuales sobre la obligación precontractual de información, una perspectiva europea", Revista Vniversitas, n. ${ }^{\circ}$ 117, 2008, 125; Gallo, P., Contratto e buona fede: buona fede in senso oggetivo e transformazioni del contratto, Milán, Utet Giuridica, 2014, 267; Alonso PÉrez, M. T., "La función de las obligaciones precontractuales de advertencia en la formación del contrato de servicios (estudio de derecho contractual europeo)", Indret Revista para el Análisis de Derecho, n. 3 , 2012, 14; BednARZ,Z., "Breach of information duties in the B2C e-commerce: adequacy of available remedies", Revista D'internet, Dret I Politica, n. ${ }^{\circ} 22,2016,5$.

6 De la MaZa, El suministro..., cit., 22.

7 De la Maza señala que "La información es el antídoto de la ignorancia, por lo mismo, si el problema se encuentra en la falta de información de los consumidores, entonces el remedio es, precisamente, la información. De ahí fluye, con toda naturalidad, que una de las técnicas más frecuentes para nivelar 
provoca la asimetría informativa debería formularse sobre una base ya existente de deberes de información -entendidos como deberes de conducta- y elaborar una propuesta que permita asentar una estructura de deberes que en su conjunto permitan decidir racional y libremente, lo cual quiere decir que no basta con recibir la información, esta debe ser comprendida ${ }^{8}$. Este es el cómo, a nuestro juicio.

De lo dicho, hemos estructurado una investigación en dos etapas. Una primera etapa que tiene por objeto analizar el deber de información como instrumento que permite al contratante del seguro tomar la decisión de contratar de modo racional y libre, y una segunda etapa que buscará precisar los efectos derivados del incumplimiento de tal deber. En este trabajo nos abocaremos a la primera etapa mencionada y, daremos cuenta, en primer lugar (I), del deber de información desde una visión panorámica en el caso del seguro; en segundo lugar (II), revisaremos el deber de información desde la perspectiva del seguro como instrumento de tutela a favor del asegurado; en tercer lugar (III), identificaremos en nuestro ordenamiento jurídico el régimen legal del deber de información sobre el contenido contractual para el caso de los seguros y los sujetos obligados a su cumplimiento, para terminar (IV) analizando el deber de entrega de información sobre el contenido contractual, por un lado, y el deber de asesoramiento, por el otro. Finalmente entregaremos nuestras conclusiones.

\section{Una visión panorámica del deber de información en el seguro}

Sobre lo que hemos señalado en el acápite introductorio y, desde una perspectiva puramente jurídica, conviene tener presente que la doctrina se ha ocupado de dejar asentado que en materia de contratos, tanto en el iter de formación como durante su cumplimiento, se dan distintos niveles de desequilibrio negocial, siendo una de las razones los supuestos de asimetría de información, especialmente en la contratación con consumidores ${ }^{9}$. Esta fenomenología de la asimetría informativa provoca un desbalance o desequilibrio en las relaciones negociales, que trastocan la justicia contractual tanto desde la dimensión procedimental como desde la material ${ }^{10}$. Frente

la desigualdad entre proveedores y consumidores sea el suministro de información a los consumidores. Ese es el cómo". De LA MAZA, El suministro..., cit., 23.

8 Frente al problema de la defectuosa comprensión de los datos, Peñas Moyano plantea la necesidad de apuntar en dos vías: la calidad de la información y una mejora de la cultura financiera de los destinatarios. Peñas Moyano, Relaciones entre..., cit., 677. En materia de consumidores la claridad en la información sería una exigencia del denominado "principio de transparencia". En este sentido, por todos, LóPEz, P., "La tutela precontractual en la ley 19.496: su configuración, alcance y eventual convergencia con aquella propia de la contratación civil", Revista Chilena de Derecho, 2019, vol. 46, n. ${ }^{\circ} 2,402$.

9 Pirilli, La fase precontrattuale..., cit., 418.

10 Sobre el equilibrio contractual como imperativo de justicia contractual y principio del derecho, por todos, LóPEz, P., "El principio de equilibrio contractual, en el código civil chileno y su particular importancia como fundamento de algunas instituciones del moderno derecho de las obligaciones en la dogmática nacional", en Revista Chilena de Derecho Privado, n. . 25, 2015, 111 y ss. Para Gallo, la problemática de la asimetría informativa está estrechamente vinculada con las exigencias de la 
a este estado, los ordenamientos jurídicos han tendido a introducir diversos mecanismos que tienen por objeto morigerar o disminuir los efectos del desequilibrio negocial, en fin, proteger a quien se sitúa en una posición de desventaja o debilidad ${ }^{11}$.

En este contexto, y sobre la base de la buena $\mathrm{fe}^{12}$, se ha propuesto la existencia de deberes de conducta que permiten reequilibrar la relación entre quienes buscan celebrar un contrato en particular ${ }^{13}$. De tales deberes de comportamiento -en el sentido de corrección y lealtad que se deben los contratantes ${ }^{14}$ - destacamos los deberes de información ${ }^{15}$. Luego ha sido el legislador quien recogiendo las exigencias de la bona fides ha explicitado estos deberes dotándolos de un contenido y unas formas de materialización concreta ${ }^{16}$.

Estas propuestas doctrinarias sobre los deberes de información -recogidas con mayor o menor énfasis dependiendo del sistema jurídico particular- apuntan a presentar una alternativa frente a las bases fundamentales de los procesos de codificación decimonónica, cuyo centro fue la libertad contractual y, en tal contexto, la regla general de encontrarse las partes en igualdad de condiciones ${ }^{17}$, por lo que todo contrato era necesariamente justo ${ }^{18}$. Quit dit contractuel dit juste ${ }^{19}$. Tales cimientos

justicia contractual. Gallo, Contratto e buona fede..., cit., 271. Por su parte, Muñoz Paredes, sostiene que "El contrato de seguro constituye un ejemplo muy vivo de asimetría informativa en la fase precontractual”. MuÑoz PAREdes, M. L., El deber de declaración del riesgo en el seguro, Pamplona, Aranzadi, 2018, 19.

11 Véase De la MAZA, El suministro..., cit., 22.

12 Véanse Gómez Calle, E., Los deberes precontractuales de informacion, Madrid, La Ley, 1994, 14; Llobet, J., El deber de información en la formación de los contratos, Madrid, Marcial Pons, 1996, 11; Musy, A., Il Dovere de informmazione, Trento, Università degli Studi di Trento, 1999, 1; HinEsTROSA, F., El deber de sinceridad del tomador del seguro en su declaración del estado del riesgo, en Revista Iberolatinoamericana de Seguros, n. ${ }^{\circ}$ 27, 2007, 124; DE LA MAZA, Límites..., cit., 26.

13 En el caso del contrato de seguro la buena fe está presente con énfasis en todos los iters negociales. Véase De LoREnzi, V., "Contratto di assicurazione e dichiarazioni inesatte e reticenti sul rischio dell'assicurato", en Assicurazioni, Rivista de Diritto, Economia e Finanza delle Assicurazzioni private, $.^{\circ} 2,2014,201-202$. Conviene destacar que en 2015 en Inglaterra se incorporaron relevantes modificaciones en orden al principio de buena fe (utmost good faith), que alteran la tradicional estructura de deberes de información en el seguro. Véase MACDonald, P., The fair presentation of commercial risks under the insurance act 2015, en Clarke, M. y SoYer, B. (eds.) The Insurance Act 2015, A New Regimen for Commercial and Marine Insurance Law, New York, Routledge, 2017, 12 ss.

14 Sobre el sentido de la buena fe en el actuar honesto en el negocio jurídico, véase por todos DE LOS Mozos, J. L., El principio de buena fe. Aplicaciones prácticas en el derecho español, Barcelona, Bosch, 1965, 24 ss.

15 Sobre el desarrollo doctrinal de los deberes de información, véase Ríos, R., El deber precontractual de declaración del riesgo en el seguro de daños, Santiago, Thomson-Reuters, 2014, 14-15.

16 Sobre la atipicidad y tipicidad en materia de deberes de información véanse DE LA MAZA, Los límites..., cit., 177 ss.; Gallo, Contratto e buona fede..., cit., 261.

17 Véanse Gómez Calle, Los deberes..., cit., 11.

18 Barrientos, M., Daños y deberes en las tratativas preliminares de un contrato, Santiago, Legal Publishing, 2008, 49.

19 Cada parte debe cuidar de sus propios intereses (caveat emptor). Véanse Musy, Il Dovere..., cit., 39; De la Maza, Los límites..., cit., 182; Gallo, Contratto e buona fede..., cit., 261. 
de la codificación del siglo XIX se han transformado en insuficientes ${ }^{20}$. El estado de la contratación ha cambiado sustancialmente, en especial por la incorporación y masificación de la contratación estandarizada mediante condiciones generales de la contratación ${ }^{21}$ que se integran, por lo general, a contratos de adhesión ${ }^{22}$ y con consumidores $^{23}$, lo cual da lugar a supuestos de desequilibrio. Se suma a ello la existencia de contratos con un alto contenido técnico y comercialización en un contexto por medios no tradicionales - virtual o electrónico- como ocurre en el caso del negocio bancario y de seguros ${ }^{24}$. La especialización técnica ${ }^{25}$ y profesional de los proveedores $^{26}$ aumenta los niveles de desequilibrio, debido a la inexperiencia e ignorancia del profano ${ }^{27}$. Así, a mayor especialización mayor será el supuesto de asimetría, dando cuenta de un evidente desbalance ${ }^{28}$.

El deber de información es, entonces, un deber de comportamiento que busca dejar a las partes en un estado de conocimiento adecuado del negocio jurídico concreto. Para el caso del seguro, que permita al asegurado conocer con la mayor claridad y certeza posible el contenido del contrato (cobertura y precio) y que sus intereses de protección queden satisfechos en el mayor grado que pueda alcanzarse. Se trata, finalmente, de cómo confluyen el consentimiento negocial y el cumplimiento del contrato ${ }^{29}$.

Sobre cómo informar de manera tal que el contratante del seguro quede en la mejor posición posible de comprender el contenido del contrato, en nuestra opinión, debemos considerar que el ordenamiento jurídico impone un deber de información

20 Zimmermann, R., El nuevo derecho alemán de las obligaciones, Barcelona, Bosch, 2008, 184 ss.

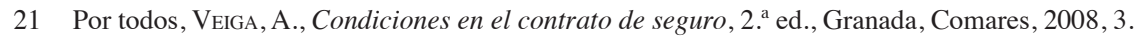

22 Según Mas, el carácter de adhesión subsiste en la contratación electrónica de seguros. MAs BADíA, M. D., "El contrato electrónico de seguro: formación del contrato y tutela del usuario", en Revista Aranzadi de Derecho y Nuevas Tecnologías, n. ${ }^{\circ}$ 38, 2015, 69.

23 Véase Quintáns, Información y conflicto..., cit., 199.

24 Hinestrosa, El deber de sinceridad..., cit., 124.

25 Sobre la información técnica en el seguro como causa de asimetrías, véase PIRILLI, La fase precontrattuale..., cit., 418. En este mismo sentido, véase PeÑas Moyano, Relaciones entre ..., cit., 670

26 Como señala Veiga, hoy en día “quien conoce la técnica del seguro, quien utiliza y emplea mecánicas y métodos cuando no hipótesis de probabilidades en base a estudios, en base a tablas actuariales, a índices de siniestralidad, etc., es la entidad aseguradora". Veiga, Condiciones..., ob. cit., 3.

27 Como sostiene Gómez Calle, "la ignorancia de uno de los contratantes puede quedar justificada por la imposibilidad de obtener por sí solo la información precisa”. Gómez CALLE, Los deberes..., cit., 15. En el caso de los seguros con componentes de inversión, la dificultad en la comprensión del contenido del contrato se hace aún más evidente. Véase Quintáns, Información y conflicto..., cit., 200. Khoury sostiene que lo que justifica un deber de información en sentido lato es el desequilibrio de conocimiento y aptitudes de una de las partes. KHOURy H., L'information et le conseil dus au preneur d'assurances, Marseille, Presses Universitaires D'Aix-Marseille, 2011, 25.

28 Esta concepción parte de la base que quien está en una posición de debilidad es el asegurado, en consecuencia, se crean mecanismos destinados a protegerlo. Ríos, El deber..., cit., 33.

29 De la Maza sostiene que "los deberes precontractuales de informar constituyen una manifestación del suministro de información como técnica para proteger a la parte más débil en una relación contractual caracterizada por la presencia de asimetrías informativas”. DE LA MAZA, Límites..., cit., 120. 
en un sentido omnicomprensivo ${ }^{30}$-funcional en su integridad o, dicho de otra manera, con un sentido teleológico común- que conforma un proceso compuesto por deberes de conducta destinados a lograr la comprensión del contenido contractual. Estos deberes son el deber de entrega o suministro material de datos y el posterior deber de asesoramiento. Este último deber de conducta, no se trata, como sostiene Gómez Calle, de un deber adicional al deber de información ${ }^{31}$ : por el contrario, es parte de este ${ }^{32}$ en la mirada omnicomprensiva que proponemos.

Si bien el suministro de información y el posterior asesoramiento constituyen deberes que poseen una autonomía conceptual, son interdependientes en términos funcionales. Su aislamiento o separación en la perspectiva de la determinación de su incumplimiento sería irrelevante. El incumplimiento de uno o del otro impediría, finalmente, la satisfacción de los intereses que el asegurado tuvo en cuenta al momento de contratar, desajustándose de la necesaria concurrencia de un consentimiento racional y libre ${ }^{33}$.

\section{El deber de información como instrumento de tutela a favor del asegurado, en su sentido omnicomprensivo}

Hay doctrina que al abordar el deber de información distingue entre suministro de datos (información neutra o mera información), advertencia y consejo, con el objeto de precisar los contornos de cada uno de dichos deberes, su ubicación en los ámbitos contractual o precontractual, y luego abordar entre los distintos efectos que provocaría el incumplimiento de tales obligaciones ${ }^{34}$. En este contexto la concurrencia de uno u otro deber (información, consejo y advertencia) dependerá de las exigencias de la propia ley para casos concretos, por lo que habrá supuestos en los que la entrega o suministro de datos satisface el cumplimiento del deber de información y otros supuestos en los que no, debiendo concurrir otros deberes como el consejo y la advertencia (o asesoría agrupando a ambos), como es el caso de los seguros.

30 La doctrina francesa ha propuesto la existencia de un deber de información lato sensu, justificado en un deber de cooperación que se deben las partes. A su vez, este deber de cooperación de sustenta en el principio de solidaridad contractual, que obliga a las partes a ocuparse de los intereses del cocontratante. Por todos, Khoury, L'information..., cit., 21.

31 Gómez Calle, Los deberes..., cit., p. 120.

32 Llobet, El deber..., cit., 34.

33 Véanse De la Maza, límites..., cit., 25 ss.; Peñas Moyano, M. J., "Obligaciones generales de información”, en Bataller, J. y Quintáns, M. R. (dirs.), Distribución de seguros privados, Madrid, Marcial Pons, 2019, 582.

34 Véanse Fabre-Magnan, M., De l'obligation d'information dans les contrats, Paris, Librerie Général de Droit et de Jurisprudence, 1992, 7 ss.; Barros E. y Rioseco A., "Responsabilidad de quien da un mal consejo", en VidAL, A., y otros (dirs.), Estudios de Derecho Civil x. Jornadas Nacionales de derecho Civil, Santiago, Thomson-Reuters, 2015, 633 ss.; GoldEnBERG, J. L., "Los contornos del deber de consejo como expresión de la colaboración y como técnica de protección", Revista de Derecho Universidad de Concepción, n. ${ }^{\circ} 244,2018,28$ ss. 
Pues bien, como hemos advertido, en nuestra opinión el deber de información para el caso concreto del seguro tiene necesariamente una dimensión omnicomprensiva, y cada uno de los deberes de conducta que lo componen forma parte de un proceso único dada la interdependencia de tales deberes con miras en un consentimiento libre e informado. Esto quiere decir que el cumplimiento pleno del deber de suministro de datos y el del deber de asesoramiento tienen una vinculación inseparable. La distinción relevante dirigida a determinar el contenido del deber de informar en el sentido omnicomprensivo que formulamos está en los sujetos obligados a su cumplimiento, pues su contenido difiere, según veremos más adelante.

Con el objeto de asentar nuestra propuesta, en los acápites que siguen revisaremos (A) la función del deber de información en el contenido del contrato de seguros, luego (B) identificaremos a los sujetos obligados al cumplimiento de tales deberes, para finalmente $(\mathrm{C})$ analizar el deber de suministro de información y el deber de asesoramiento, como deberes de conducta que integran un deber de información en sentido omnicomprensivo.

\section{A. El deber de información y su función en la determinación del contenido del contrato de seguro}

En materia de seguros, el contenido contractual tiene como eje central el riesgo asegurable $^{35}$. En este sentido, determinado en concreto el riesgo y delimitado en sus dimensiones cualitativa y cuantitativa, el contrato podrá celebrarse y conferirá al tomador o asegurado un amparo o cobertura específica por el pago de un precio determinado o determinable, la prima ${ }^{36}$. Son, por consiguiente, los datos sobre el riesgo asegurable los que permiten determinar el contenido contractual -en lo esencial, cobertura y precio- que ambas partes, asegurador y asegurado, deben tener claros con el fin de lograr de la mejor manera la satisfacción de los intereses que tuvieron presentes al contratar. El conocimiento del riesgo y sus posteriores cobertura y precio como elemento correlativo se logra mediante el despliegue de deberes de información impuestos a los contratantes. Por un lado, el deber precontractual sobre declaración del riesgo ${ }^{37} \mathrm{y}$, por el otro, el deber de información a cargo del asegurador o del corredor de seguros sobre las condiciones del seguro contratado.

En materia de contrato de seguro y deberes de información, debemos distinguir dos supuestos que conformarían, a su vez, un límite en materia de información, a lo menos en cuanto a su contenido. Nos referimos a los seguros de grandes riesgos y los seguros con consumidores ${ }^{38}$. En el primer caso, la problemática de la asimetría es más

35 Ríos, El deber..., cit., 65 ss.

36 Ríos, El deber..., cit., 65 ss.

37 Un detalle en Ríos, El deber..., cit., 7 ss.

38 Para Peñas Moyano la intensidad del deber de información dependerá "del tipo de tomador y del tipo de contrato de seguro que se celebre”. PeÑas Moyano, Relaciones entre..., cit., 678. 
bien difusa, pues el grado de conocimiento del riesgo, de las condiciones de cobertura ofrecidas en el mercado y de la experiencia del contratante permitiría determinar el nivel de asimetría y, en consecuencia, el grado de protección o tutela exigido, el que es probablemente innecesario ${ }^{39}$. Para este supuesto, el análisis caso a caso será lo determinante. En el caso de los seguros contratados entre un asegurador y un consumidor $^{40}$, en nuestra opinión, no existirían mayores cuestionamientos. En este sentido, todo supuesto de relación de consumo supone la existencia de un desequilibrio negocial que tiene su origen, entre otros factores, en la fenomenología de la asimetría de información, que para el caso del seguro se muestra más evidente o de manera más enfática, pues el consumidor de seguros no posee los medios para precisar los elementos relevantes del riesgo que pretende traspasar al asegurador ${ }^{41}$, no está en condiciones de conocer con claridad el contenido del contrato-especialmente por sus particularidades técnicas-, por un lado, y por el otro, no dispone de las herramientas para identificar las distintas alternativas de cobertura y precio, todo con el objeto final de tomar una decisión razonada y orientada a la satisfacción del interés de protección que busca al contratar un seguro ${ }^{42}$.

De lo dicho, entonces, en el proceso de decisión de contratar -y su racionalidad, entendida como una elección adecuada a la satisfacción de un interés concreto y, por consiguiente, libre- el deber de información cumple un papel fundamental en el seguro. Por una parte, el deber del contratante de declarar sobre el estado del riesgo ${ }^{43}$ $y$, por la otra, el deber de información sobre el contenido del contrato que recae en el asegurador o en el intermediador, según sea la contratación directa o no. Sobre este último deber de conducta nos abocaremos en específico a continuación.

Bajo lo que hemos contextualizado con anterioridad y en cuanto a nuestra propuesta sobre el deber de información en el seguro, es nuestra opinión que nuestro ordenamiento jurídico impone un deber de información que se agotaría en dos etapas o quizás en tres fases y, en este sentido, debe ser considerado desde una perspectiva

39 Sobre ello, Quintáns sostiene que "Indudablemente, cuando los contratos se concluyen con clientes no profesionales, está presente la consabida asimetría informativa ya que mientras el profesional tiene pleno conocimiento del contrato y del mercado, el consumidor no". QuiNTáns, Información y conflicto..., cit., 199. Sobre el régimen de tutela del asegurado consumidor en el derecho chileno, véase por todos Barrientos, M., Normas sobre la protección de los derechos de los consumidores en el contrato de seguro en Chile, Madrid, Fundación Mapfre, 2012, 25 ss.

40 Es opinión de Zimmermann, que el derecho opta por un enfoque tipológico: concede protección a una de las partes que considera débil o en desventaja frente a la otra. Zimmermann, R., El nuevo Derecho..., cit., 185. En el caso concreto del contrato de seguro, véanse VeIGA, Condiciones..., cit., 15; Beckmann, R., Versicherungsrechts-Handbuch, München, Verlag C. H. Beck, 2011, 18.

41 Véase Ríos, El deber..., cit., 32 ss.

42 En esta perspectiva, el deber de información obliga a quien posee la ventaja a renunciar a ella en todo o en parte, en favor de quien es considerado débil o en desventaja en la relación negocial, sea esta precontractual o contractual. Gallo, Contratto e buona fede..., cit., 267.

43 Sobre el deber precontractual de declaración del riesgo, véase por todos Ríos, El deber..., cit., 7 ss. 
omnicomprensiva ${ }^{44}$. Al referir omnicomprensiva quisiéramos formular que consiste en un deber de conducta inserto en un proceso que tiene por objeto dejar al tomador o asegurado en la mejor posición posible con el fin de conocer los términos contractuales, de manera tal que, ocurrido el siniestro- verificado el riesgo asegurado-, sus intereses de amparo queden satisfechos.

La primera fase del deber de información se identifica con la entrega de información o suministro de datos sobre el contenido del contrato; una segunda etapa correspondería al asesoramiento; $y$, finalmente, un tercer paso sería el deber de advertencia sobre las ventajas o desventajas de las coberturas ofrecidas. En relación con esta última etapa adelantamos que, en nuestra opinión, se trata más bien de un deber que se funde o integra al deber de asesoramiento. De este modo, son dos deberes de conducta que, si bien poseen una autonomía conceptual, en su función y en la perspectiva de su inejecución, son interdependientes. Esta interdependencia quiere decir que el incumplimiento de uno o de otro nos sitúa en un supuesto de inobservancia del deber de información en su sentido omnicomprensivo, que daría lugar a los diversos efectos previstos en la ley ${ }^{45}$.

Lo que hemos propuesto se justifica por cuanto la oferta de celebrar el contrato de seguro contiene una serie de datos de difícil o imposible comprensión de parte del asegurado. Así, la correcta entrega de información -mero suministro de datos-y su adecuada comprensión requieren un acto posterior de asesoramiento o consejo. En fin, el receptor de la información -que para el caso que nos interesa es el tomador del seguro- debe ser puesto en la posición frente a diversas alternativas, decidir si contrata o no, y, si contrata optando por alguna de las alternativas ofrecidas, saber de qué manera su interés de amparo quedará satisfecho al momento de verificarse el riesgo asegurado, el siniestro.

De lo señalado con anterioridad, se demuestra $a b$ initio la interdependencia funcional que hemos propuesto entre el deber de entrega de información y el deber de asesoramiento, pues en ambos casos confluye la misma función, dejar al contratante del seguro en la mejor posición posible de conocimiento del contenido contractual.

Por su parte, la independencia conceptual o separación entre el deber de entrega de información y asesoramiento que presentan algunos autores ${ }^{46}$ se justificaría únicamente para determinar con claridad la frontera entre uno y otro en cuanto a su contenido, considerando, como veremos más adelante, que son diversos los sujetos obligados al cumplimiento de este deber de conducta. Es relevante precisarlo en este sentido, pues si hay incumplimiento en la fase inicial de entrega de información

44 Fabre-Magnan propone un análisis del deber de información distinguiendo entre información, consejo y advertencia, precisando que no se trata de categorías independientes en el sentido de asentar una especie de suma divisio. Fabre-Magnan, De l'obligation..., cit., 7 ss.

45 Sobre las consecuencias del incumplimiento al deber de información, véase Alonso Pérez, La función..., cit., 15 .

46 Se trata en nuestra doctrina de la propuesta formulada por GoldENBERG, Los contornos..., cit., 28 ss. 
sobre el contenido del contrato, la etapa siguiente de asesoramiento, aunque observada, es insuficiente para dar cumplida la función del deber de conducta de dejar al contratante del seguro en la mejor posición posible para la toma de la decisión razonada y libre de contratar. De la misma manera, si la fase de asesoramiento no se cumple, la entrega de información, aunque suficiente, no permite finalmente arribar al cumplimiento de la función del deber de información en tanto deber de conducta y en el sentido omnicomprensivo que hemos propuesto. Lo anterior se debe a que no es satisfactorio entregar información sobre el contenido del seguro, pues quien recibe los datos -el tomador o asegurado- no está en condiciones de reflexionar o desceñir por su verdadera conveniencia, debido, como ya hemos advertido al inicio de esta exposición, al alto nivel técnico de este contrato en su contenido y a la complejidad de su forma contractual ${ }^{47}$.

Como se ve, en uno u otro caso, ya sea por información defectuosa o incompleta o por falta o defecto en el asesoramiento, habrá frustración en la satisfacción del interés del contratante del seguro; por consiguiente se dará un estado de incumplimiento que provoca los efectos jurídicos previstos en la ley, que, como ya hemos adelantado $-\mathrm{y}$ profundizaremos en una segunda etapa de nuestra investigación-, podrían ir desde la ineficacia del seguro y su conservación hasta supuestos de responsabilidad e indemnización, como sanciones administrativas.

\section{B. Sujetos obligados al cumplimiento del deber de información en el contrato de seguro}

La identificación de los sujetos obligados al cumplimiento del deber de información en el seguro bajo el ordenamiento jurídico chileno posee una fuente dual. En esta dualidad normativa podemos distinguir una de origen legal y otra administrativa ${ }^{48}$. Es relevante esta distinción, por cuanto la mirada desde la fuente legal conlleva consecuencias desde una dimensión estrictamente negocial o contractual para los casos de incumplimiento del deber de información -nulidad, conservación del contrato, responsabilidad-y, desde la dimensión administrativa, las consecuencias serán infraccionales sin alcanzar al contrato, necesariamente ${ }^{49}$.

47 Sobre la complejidad técnica y económica del seguro, véase SÁnchEZ SANTOS, J. M., "Estructura del mercado y competencia en la distribución de seguros: una perspectiva económica", en QuiNTÁNs, M. R. (dir.), Estudios sobre mediación de seguros privados, Pamplona, Aranzadi, 2013, 29 ss.

48 En opinión de Pirilli, la asimetría informativa interesa en una doble dimensión: por una parte, la perspectiva del contenido del contrato y el desequilibrio que provoca la asimetría de información y, por el otro, la actividad de la empresa de seguros y el equilibrio del mercado. PIRILli, La fase precontrattuale..., cit., 418. Véase Gallo, Contrato e buona fede..., cit., 267 ss.

49 Sobre este tópico, Landini sostiene que además de los remedios civiles para el caso del incumplimiento de deberes de información a cargo de quienes comercializan o distribuyen seguros, encontramos sanciones administrativas, en concreto sanciones pecuniarias y de otra índole. LANDINI, S., "Sanzioni amministrative e trasparenza nei rapporti assicurativi, pubblico e privato nei mercati regolamentati", en Assicurazioni, Rivista de Diritto, Economia e Finanza delle Assicurazzioni private, n. ${ }^{\circ}$ 3, 2014, 413. 
La dimensión legal del deber de información se encuentra contenida en las normas sobre comercialización de seguros ${ }^{50}$, en específico en el artículo 57 del Decreto con Fuerza de Ley 251 sobre Compañías de Seguros (en adelante, DFL 251), el Decreto Supremo 1055 que contiene el reglamento sobre Auxiliares del Comercio del Seguro (en adelante, DS 1055), y además, en los artículos 529 n. $.^{\circ} 1,514$ inciso 2. ${ }^{\circ}$ del Código de Comercio (en adelante, c. co.) y el artículo 17b de la Ley Sobre Protección de los Derechos de los Consumidores n. 19.496 (en adelante, LPC).

A la regulación legal que hemos referido con anterioridad se suma la Norma de Carácter General número 420 (en adelante, NCG 420) sobre principios de conductas de mercado $^{51}$, que busca permear en la actividad del aseguramiento ciertos tipos de conducta basados en principios con el fin de resguardar la estabilidad del mercado financiero en general.

De acuerdo con las normas legales y administrativas citadas, podemos distinguir dos vías de materialización de la comercialización o distribución de seguros: por un lado, la venta directa realizada por el asegurador y, por el otro, la venta realizada a través de corredores ${ }^{52-53}$.

En resumen, y para los efectos del cumplimiento del deber de conducta -o de información omnicomprensivo- que analizamos en esta oportunidad, identificamos dos sujetos: el asegurador y los corredores de seguros ${ }^{54}$.

El contenido y el sentido del deber de información difieren en la etapa de asesoramiento dependiendo de si el sujeto obligado a su cumplimiento es el asegurador o

50 Distribución en los términos de la normativa dictada por la Unión Europea.

51 La NCR 420 se basa en los denominados "Principios Básicos de Conducta de Mercado: desarrollo de un modelo de supervisión para la industria aseguradora", de septiembre de 2015, propuestos por la Comisión para el Mercado Financiero (ex svs). Por su parte, estos principios tendrían como fuente el conjunto de principios para la protección del cliente financiero recomendados por la OECD y los Insurance Core Principles emitidos por la International Association of Insurance Supervisors. Unido a lo anterior, el texto de la NCG 420 se sustenta, además de los principios de conductas de mercado, en los Principios de Gobierno Corporativo aplicables a los aseguradores y corredores de seguros, contenidos en la Norma de Carácter General n. 309 de 2011. En este sentido, véase Principios Básicos de Conducta de Mercado: desarrollo de un modelo de supervisión para la industria aseguradora, 3-4, disponible en [www.svs.cl/portal/principal/605/articles-17329_doc_pdf.pdf].

52 Véanse Contreras, O., Derecho de Seguros, 2. ed., Santiago, Thomson-Reuters, 2014, 131 ss.; NASSER, Seguros de..., cit., 120 ss.

53 Un detalle sobre el estatuto legal que rige a los corredores de seguro en ConTrERAs, O., "Estatuto legal de los corredores de comercio en general, de los corredores de seguro en particular y prescripción de su responsabilidad", en Escobar, M. (ed.), Estudios de Derecho Comercial. Séptimas Jornadas Chilenas de Derecho Comercial 2016, 2017, 491 ss.

54 La ley distingue diversos sujetos: los denominados "agentes de venta", los corredores de seguros independientes, los corredores de seguros vinculados a la banca, los corredores de seguros vinculados al denominado negocio del retail, entre otros. En el caso de los agentes de venta, los excluiremos de la intermediación independiente, pues, como el mismo citado artículo 57 del DFL 251 dispone, estos "[...] actúan por cuenta de una compañía, no pudiendo prestar tales servicios en más de una entidad aseguradora [...]", por lo que los seguros por ellos comercializados deben ser considerados en el supuesto de venta directa. Lo anterior queda reforzado en el inciso $4 .^{\circ}$ del mismo artículo 57 del DFL 251 al disponer que "serán de responsabilidad de la entidad aseguradora las infracciones, errores u omisiones en que puedan incurrir los agentes de ventas en el desempeño de su actividad". 
es el corredor de seguros. Por otro lado, el régimen legal del deber de información a cargo del asegurador permite completar el contenido del deber de informar en el caso del corredor. A ello nos abocaremos en los acápites siguientes.

\section{Deber de entrega de información sobre el contenido del contrato de seguro}

Nuestro ordenamiento jurídico se ocupa del deber precontractual de información del asegurador en los artículos 514 inciso $2 .^{\circ}$ y 529 número 1 del c. co. ${ }^{55}$.

Para el caso del corredor de seguros, el artículo 57 del DFL 251 no impone un deber de entrega de información en los términos del citado artículo 514 del c. co. Tal deber de suministro de datos ${ }^{56}$ tiene su base en el artículo 10 n. 2 del DS 1055, que impone al corredor el deber de "informar a sus clientes sobre las condiciones del contrato y, en especial, sobre la extensión del seguro pactado y sus adicionales, sobre los riesgos y situaciones excluidas de la cobertura, alcance de las franquicias o deducibles a la misma, cláusula de prorrateo, forma y plazos de pago, efectos de su incumplimiento y, en general, toda la información necesaria para ilustrar mejor su decisión".

No obstante el silencio del citado artículo 57 del DFL 251, en nuestra opinión las exigencias que el c. co. imponen al asegurador en la comercialización directa deben extenderse y aplicarse íntegramente a los corredores de seguros, pues de esta manera lo explicitó el legislador durante la tramitación de la ley $20.667^{[57]}$.

Si revisamos la historia de la ley 20.667, podemos constatar que nuestro legislador fundamenta los términos de los artículos 514 y 529 del c. co. en la necesidad de unificar el régimen de responsabilidad del asegurador que contrata con el asegurado de manera directa o sin intermediación, respecto de aquellos casos en los que contrata por medio de un corredor de seguros ${ }^{58}$. Claramente, el legislador buscó unificar el criterio del artículo 10 del citado DS 1055 para el caso de la denominada "contratación directa", si del deber de información en el seguro se trata.

La innovación que introduce la ley 20.667 apunta a uniformar o crear una especie de estándar general extendiendo el ámbito subjetivo del deber de información, que no solo alcanza al corredor de seguro, sino también al asegurador ${ }^{59}$. De acuerdo

55 En este sentido, véase BARRIENTos, M., "Nuevos deberes precontractuales de información en los certificados de cobertura provisorio, definitivo y la propuesta del contrato de seguro", en Revista de Derecho Universidad Católica del Norte, n. ${ }^{\circ}$ 1, 2015, 80 ss.

56 Véase Llobet, El deber de..., cit., 1996, 33.

57 Véase Historia de la Ley 20.667, 95-96, disponible en [www.bcn.cl/historiadelaley/nc/historia-dela-ley/4463/].

58 Véase Historia de la Ley 20.667, 95-96, disponible en [www.bcn.cl/historiadelaley/nc/historia-dela-ley/4463/].

59 Barrientos califica esta obligación como un "deber de asesoría integral”. BARRIENTOS, M., "Artículo 529 n. ${ }^{\circ}$ 1, Obligaciones del asegurador (el deber precontractual de información)”, en Ríos, R. (dir.), El contrato de seguro. Comentarios al título viI Libro II del Código de Comercio, Santiago, ThomsonReuters, 2015, 336. 
con lo señalado, entonces, la revisión y el análisis del deber de entrega de datos sobre el contenido del contrato que proponemos a continuación se extienden tanto al asegurador como al corredor de seguros.

Conforme al citado artículo 514 inciso 2. ${ }^{\circ}$ del c. co., el asegurador durante el proceso de formación del seguro debe "[...] entregar al tomador, por escrito, toda la información relativa al contenido del contrato que se celebrará. Ésta deberá contener, al menos, el tipo de seguro de que se trata, los riesgos cubiertos y las exclusiones; la cantidad asegurada, forma de determinarla y los deducibles; la prima o método para su cálculo; el período de duración del contrato, así como la explicitación de la fecha de inicio y término de la cobertura". El texto legal citado apunta a resolver la problemática cuantitativa del deber de información, estableciendo un suministro mínimo de datos sobre el contenido del contrato a favor del asegurado.

En nuestra doctrina, Contreras al analizar el citado artículo 514 del c. co. lo hace bajo la denominación de "propuesta informada" ${ }^{60}$. Con ello ha querido decir que el asegurado o tomador del seguro recibe información para luego formular una propuesta, pues así se entiende del texto del inciso 1. ${ }^{\circ}$ del citado artículo 514 del c. co., al disponer que "La proposición de celebrar un contrato de seguro deberá expresar la cobertura, los antecedentes y circunstancias necesarios para apreciar la extensión de los riesgos" y de la parte inicial inciso segundo del mismo artículo, que ha dispuesto que "para los efectos" de poder elaborar la propuesta el asegurado o contratante debe ser informado previamente sobre el contenido contractual. En nuestra opinión, el citado autor propone, entonces, que existe un deber información en sentido preparatorio a la posterior oferta de contratar un seguro por parte del asegurado o tomador ${ }^{61}$. Se refiere únicamente a la dimensión de entrega material de datos sobre el contenido contractual (la dimensión cuantitativa).

Por su parte, Barrientos formula en primer lugar una crítica al vocablo propuesta definido en el artículo 513 letra q del c. co. ${ }^{62}$, y luego, al abordar el análisis sobre el citado artículo 514 señala que "no queda duda [de] que la oferta, como acto formador del contrato de seguro, consensual y de adhesión en gran parte de los casos, descansa no en el tomador o asegurado consumidor, sino más bien en el asegurador proveedor" 63 . Y agrega que "Se pretende con ello que el asegurado tenga la oportunidad de tomar conocimiento real de las cláusulas del contrato, antes de la celebración del mismo"64. Barrientos sostiene, además, que "la información servirá para reducir

Contreras, Derecho de..., cit., 2014, 152.

61 Debemos considerar que el artículo 513 letra $q$ del c. co., define propuesta como la oferta escrita de contratar el seguro, formulada al asegurador por el contratante, el asegurado o por un tercero a su nombre. Sobre el desajuste de las definiciones del artículo 513 del c. co. y el tráfico mercantil del seguro, véase Ríos, R., "Capítulo introductorio", en Ríos, R. (dir.), El contrato de seguro. Comentarios al título VIII Libro II del Código de Comercio, Santiago, Thomson-Reuters, 2015, 17.

62 Cfr. Ríos, "Capítulo...," cit., 16 ss.

63 Barrientos, “Artículo 529...”, cit., 195.

64 Barrientos, “Artículo 529...”, cit., 195. 
la asimetría entre las partes, y en esto hay una clave, debe ser clara y precisa, estar a disposición siempre. Da lo mismo si el consumidor o tomador del seguro la va a leer o si no la entiende porque su nivel de comprensión intelectual es bajo. Esto es irrelevante, lo más importante es que fue simplemente capaz de haberla leído porque la aseguradora se la puso a disposición de la forma en que manda la ley. Este es el estándar que se habrá se satisfacer [...]"65.

Nos apartamos de la propuesta de Barrientos, pues, en nuestra opinión, no es suficiente que por resultado de la entrega material -o virtual- de la información, el asegurador cumpla. Es necesario satisfacer de la mejor manera la exigencia de contenido y comprensión. Por esta razón debemos considerar el deber de información en un sentido omnicomprensivo, siendo la entrega de datos una primera etapa. Es decir, constituye un cumplimiento parcial y por consiguiente insatisfactorio si se mira aisladamente y no en un sentido integrado y funcional conectado con el deber de asesoramiento.

De vuelta al texto del citado inciso segundo del artículo 514 del c. co., podemos sostener que el legislador chileno explicitó o tipificó ${ }^{66}$ un deber de entrega de información a cargo del asegurador, fijando un nivel mínimo de información sobre el contenido contractual que debe ser entregado al contratante o asegurado. Esta es la primera fase del deber de conducta destinado a lograr una decisión o elección razonada y libre, que debe considerar, a lo menos, "[...] el tipo de seguro de que se trata, los riesgos cubiertos y las exclusiones; la cantidad asegurada, forma de determinarla y los deducibles; la prima o método para su cálculo; el período de duración del contrato, así como la explicitación de la fecha de inicio y término de la cobertura".

En cuanto a la forma de materialización o cumplimiento del deber, el citado artículo 514 dispone que debe realizarse por escrito ${ }^{67}$. Esta exigencia de información por escrito puede ser material o virtual. En este último caso, se debe cumplir con lo dispuesto en el artículo 12A de la LPC, norma que exige un soporte electrónico -o virtual- con un acceso claro, comprensible e inequívoco de las condiciones del contrato y la posibilidad de almacenar o imprimir la información ${ }^{68}$.

66 En este sentido, De la Maza, Límites..., cit., 177.

67 En su análisis del artículo 529 número 1 del c. co., Barrientos señala que "[...] el § 7 Information des Versicherungsnehmers de la ley, en cuanto al deber de asesoría, señala que la aseguradora deberá informar al tomador, por escrito, de sus condiciones de contratación, incluyendo los términos y condiciones generales de los seguros, con la suficiente antelación, y siempre antes de que el tomador dé su aceptación contractual. Esta información se facilitará de manera clara y comprensible, de acuerdo con el medio de comunicación empleado". BARrientos, “Artículo 529...”, cit., 339. En este mismo sentido, véase CONTRERAs, Derecho..., cit., 266. Por otra parte, el asegurador podría dar cumplimiento mediante cualquier medio tecnológico que, de certeza de la recepción de la información sobre el contenido negocial, en concordancia con lo dispuesto en el artículo 12A de la LPC, siempre y cuando, como lo exige la citada norma legal el destinatario de la información tenga "[...] acceso claro, comprensible e inequívoco de las condiciones generales del mismo y la posibilidad de almacenarlos o imprimirlos".

68 Véase Pinochet, R., “Artículo 12 A”, en De la Maza, I. y Pizarro, C. (dirs.), La protección de los derechos de los consumidores, 2013, 264 ss. 
Considerando la exigencia de suministrar la información por escrito y siguiendo nuestra propuesta sobre la necesidad de poner el foco en el cómo informar, la Comisión para el Mercado Financiero (en adelante, CMF) en el ejercicio de su función de supervisión y en el contexto de los objetivos de conductas de mercado y protección de los consumidores que le encomienda la ley, podría imponer mediante una norma concreta la implementación de un formulario similar al sugerido por la European Insurance and Occupational Pension Authority, que elaboró un documento tipo formulario o template sobre "Documento de Información sobre Producto de Seguro", en aplicación del Reglamento 2017/146 ${ }^{[69]}$. Ello se contextualizaría, además, con la implementación del sistema de supervisión basado en riesgos que busca enfatizar y promover la autorregulación, tan deseada por la agencia supervisora chilena ${ }^{70}$.

Por otra parte, en la perspectiva de la función de supervisión a cargo de la CMF, el citado artículo 514 debe leerse en complemento con la Norma de Carácter General 420 sobre principios de conductas de mercado $^{71}$, que hemos referido con anterioridad y que busca permear en la actividad de los distintos actores de la industria aseguradora ciertos tipos de conducta basados en principios, en concreto (1) trato justo a los clientes; (2) gestión de conflictos de interés; (3) protección de la información de los clientes; y (4) promoción del desarrollo del mercado con transparencia. Estos denominados "principios" confluyen en su contenido y sus objetivos con las normas legales y administrativas que conforman el estatuto jurídico del deber de información, que ya hemos referido ${ }^{72-73}$.

69 Peñas Moyano, Obligaciones..., cit., 601 ss. Véase formulario en [https://eiopa.europa.eu/Publications/Technical\%20Standards/ES_EIOPA_IPID_template_Dec_2017.pdf]. Conviene revisar, además, las exigencias del Reglamento 1286/2014 referente al "Documento de Datos Fundamentales" sobre seguros con inversión, complementado por el Reglamento 2017/653, que recoge las exigencias de la Directiva de la UE 2016/97 sobre distribución de seguros. Véase en [https://eur-lex.europa.eu/legalcontent/ES/TXT/HTML/?uri=LEGISSUM:24040303_1\&from=ES]. Las exigencias de este reglamento se encuentran recogidas en el artículo 185 del Codice della Assicurazioni Private, en los siguientes términos: "1. Le imprese di assicurazione e gli intermediari che realizzano prodotti assicurativi da vendere ai clienti redigono i seguenti documenti: a) il documento informativo precontrattuale per i prodotti assicurativi danni di cui all'articolo 185- bis, redatto in conformità a quanto stabilito dal regolamento di esecuzione (UE) 2017/1469 dell'11 agosto 2017 (DIP)". Véase en [https://www.ivass. it/normativa/nazionale/primaria/Cap.pdf].

70 Un detalle sobre la supervisión basada en riesgos y su metodología en [www.svs.cl/portal/princi$\mathrm{pal} / 605 / \mathrm{w} 3$-propertyvalue-18623.html].

71 Véase en [https://www.svs.cl/portal/principal/605/articles-17329_doc_pdf.pdf].

72 Véase texto de los ICP 253 ss. Consulta realizada en [www.iaisweb.org/page/supervisory-material/ insurance-core-principles\#]. Para un detalle sobre las normas de conducta de mercado en la UE, véase Peñas Moyano, M. J., "Conductas de mercado", en Bataller, J. y Peñas Moyano, M. J. (dirs.), III Congreso Nacional de Ordenación, Solvencia y Supervisión en Seguros Privados, Valencia, Low Cost Books, 2016, 503 ss.

73 Según lo enuncia la propia NCG 420, estos principios de conductas de mercado consisten en la implementación de "las buenas prácticas que deberían considerar las aseguradoras, intermediarios y otros agentes del mercado asegurador, tendientes a la protección de los derechos de los asegurados y público en general, considerando aspectos tales como trato justo y transparencia en la comercialización de los seguros, el pago de las indemnizaciones y otros beneficios asociados a éstos, los que permiten aportar soluciones a las llamadas fallas de mercado". Véase NCG 420, 3-4. 
Como hemos podido revisar, la primera fase del deber de información consiste en la entrega de datos sobre el contenido contractual, que debe enlazarse ineludiblemente con el deber de asesoramiento, con el fin de determinar si hay incumplimiento del deber de información omnicomprensivo que dé lugar a los efectos previstos en la ley. A continuación revisaremos el deber de asesoramiento.

\section{Deber de asesoramiento}

El deber de asesoramiento ${ }^{74}$ es un deber de comportamiento funcionalmente integrado al deber de información omnicomprensivo que analizamos. No obstante esta interdependencia e integración funcional, hay diferencias de contenido entre el deber de asesoramiento desde la perspectiva del asegurador, en relación con el mismo deber que carga el corredor de seguros. Para estos efectos, es necesario precisar conceptualmente qué quiere decir el legislador en los artículos 57 del DFL 251, inciso 5. , y 529, n. ${ }^{\circ} 1$, del c. co., al disponer que antes de la celebración del contrato el asegurador o el corredor de seguros, según la comercialización sea directa o no, debe prestar asesoría al asegurado, ofrecerle las coberturas más convenientes a sus necesidades e intereses, e ilustrarlo sobre las condiciones del contrato ${ }^{75}$.

Adelantamos que para nosotros el término asesorar tiene una doble dimensión: por una parte, aconsejar e ilustrar al asegurado o tomador del seguro sobre los datos recibidos en la fase previa de suministro de información sobre el contenido del contrato y, por la otra, un examen sobre condiciones objetivas ofrecidas en el mercado en cobertura y precio, que luego deben ser puestas a disposición del contratante del seguro en dos o más alternativas, con el objeto de tomar la decisión que se ajuste de la mejor manera a sus necesidades e intereses de protección.

Para lograr una precisión en el sentido que hemos indicado, realizaremos un análisis histórico de ambas normas legales.

\section{Revisión del precipitado histórico de los artículos 57 del DFL 251 y 529 n. 1 del c.co.}

Precisar el sentido del vocablo asesorar exige acudir a la historia de la norma. Debemos determinar los posibles criterios y fuentes, en concreto aquellos que siguió nuestro legislador en la elaboración del inciso 5. del artículo 57 del DFL 251 y luego revisar el proceso de establecimiento del artículo $529 \mathrm{n} .^{\circ} 1$ del c. co. ${ }^{76}$.

74 Para Latorre se trata de una obligación de resultado. LaTORRE, Los deberes..., cit., 222. En contra Khoury, quien sostiene que jurídicamente la obligación de información y de consejo son diferentes, pues la primera es una obligación de resultado y la segunda una obligación de medios. KHOURY, L'information..., cit., 27; en el mismo sentido GoldENBERG, Los contornos..., cit., 17.

75 Barrientos advierte sobre la similitud de texto y agrega el artículo 9 del DS 1055. BARRIENTOS, "Artículo 529...", cit., 335 ss.

76 Sobre la necesidad de recurrir al elemento histórico como método de interpretación, con el fin de 
En el sentido indicado, el título III del DFL 251 sobre "Auxiliares del Comercio de Seguros" fue introducido por nuestro legislador mediante la ley 18.814 de 1989, sustituyendo el anterior texto enunciado como "De las sociedades cuyas acciones pueden ser representativas de reservas técnicas y patrimonio de riesgo". Previo a esta norma de rango legal, nuestro ordenamiento jurídico no contenía una regulación legal específica para el caso de los corredores de seguros. El vacío legal en la regulación de corredores de seguros fue llenado por la Superintendencia de Valores y Seguros (en adelante, svs) ${ }^{77}$, órgano que en uso de sus atribuciones y vista la necesidad de regular la intermediación de contratos de seguros emitió la Circular n. ${ }^{\circ} 81$ de fecha 8 de septiembre de 1981 que señalaba en su artículo $8 .^{\circ}$ letra a como obligación del corredor la de "Ofrecer coberturas adecuadas a las necesidades e intereses de las personas que deseen asegurarse por su intermedio; ilustrar sobre las condiciones del contrato y, especialmente, sobre el monto o precio de la prima y las normas sobre prorrateo establecidas en el artículo 532 del Código de Comercio, si procediere; presentarles cotizaciones y modalidades para la cobertura que ofrecen diversas compañías, señalando las ventajas y desventajas de ellas, si el cliente así lo requiere"78.

Por su parte, nuestro legislador, al redactar el texto del inciso 5. ${ }^{\circ}$ del artículo 57 del DFL 251, que introduce mediante la ley modificatoria n..$^{\circ} 18.814$ de 1989, siguió el texto de la transcrita circular n. ${ }^{\circ} 81$ emitida por la svs ocho años antes, en $1981^{[79]}$. A su vez, esta norma de rango administrativo dictada por la svs pareciera seguir los criterios contenidos en la normativa española, en concreto la ley 117/1969, que en su capítulo II, "De los agentes de seguros en general", artículo noveno sobre obligaciones, establece una obligación de informar sobre las condiciones del contrato que se han de suscribir, en favor de la parte que trate de concertar el seguro ${ }^{80}$.

Como podemos ver, la novedad del texto que introduce la ley 18.814 al artículo 57 está en la expresión "asesorar”, sin más.

A la ley 18.814 le sigue la modificación de la ley 19.301, que introduce el inciso 6. ${ }^{\circ}$, en el citado artículo 57 del DFL 251, donde se dispone que "Los corredores deberán entregar a todos sus clientes información respecto de la diversificación de sus negocios y de las compañías con que trabajen, en la forma que determine la

elaborar una propuesta sistemática sobre la disciplina de la mediación de seguros en el derecho español, véase TiRAdo SuARez, F. y SARTi, M. A., Ley de mediación en seguros y reaseguros privados, Santiago, Thomson-Aranzadi, 2007, 65 ss.

77 La svs fue sustituida por la Comisión para el Mercado Financiero. Véase ley 21.000.

78 Véase en este sentido Ríos, R., "La obligación del asesoramiento a cargo del corredor en la fase de formación del seguro como contrato de consumo", en Escobar, M. (ed.) Estudios de Derecho Comercial. Séptimas Jornadas Chilenas de Derecho Comercial 2016, 2017, 523 ss.

79 En este sentido la historia de la ley 18.814, consultada en la Biblioteca del Congreso Nacional.

80 Constituye un antecedente de la ley 117/1969, la ley sobre control de acceso y de ejercicio de las entidades aseguradoras y su reglamento de 1912. Véase Tirado Suarez y Sarti, Ley de mediación..., cit., 66-67. 
Superintendencia"81. Esta norma busca asentar y enfatizar la independencia de los corredores de seguros, pues, como lo expresa la misma historia de su establecimiento, "Se supone que el corredor es la persona que debe informar al cliente potencial sobre todas las alternativas que ofrece el mercado, y no como ocurre en la práctica, en que lo hace sólo respecto de la compañía con la cual opera. Por lo tanto, aquí habría una modificación importante de las regulaciones relativas a los corredores de seguros para hacer más transparente su actividad" ${ }^{\prime 2}$.

El inciso 6..$^{\circ}$ del artículo 57 que introduce la ley 19.301 debe leerse en conjunto con el inciso anterior y concluir, de esta manera, que el deber de asesoramiento consiste, además del consejo o ilustración sobre el contenido del contrato, en cumplir con un deber de información en sentido objetivo, entendido este como diversas condiciones de cobertura y precio ofrecidas en el mercado de seguros que deben darse a conocer al asegurado o tomador del seguro ${ }^{83}$. Se trata del examen de objetividad.

Una segunda etapa en el tratamiento del deber de asesoramiento corresponde a la ley 20.667 del 2013, que sustituyó íntegramente el título viII del libro II del c. co. En esta oportunidad el legislador chileno incorporó -como ya hemos adelantado-el artículo 529 numeral 1, que impone al asegurador en el caso de la comercialización directa el deber de "prestar asesoría al asegurado, ofrecerle las coberturas más convenientes a sus necesidades e intereses, ilustrarlo sobre las condiciones del contrato [...]". Como podemos ver, es un texto idéntico al contenido en el artículo 57 del DFL 251. La razón de la ampliación del ámbito subjetivo del obligado al deber de asesoramiento, que incluiría no solo a los corredores sino además a los aseguradores, subyace en la historia de la ley, pues el legislador quiso uniformar los criterios normativos en materia de deber de información si de comercialización de seguros de trata, como ya hemos advertido ${ }^{84}$. El estado anterior a la reforma que imponía una obligación de asesoramiento solo a cargo de los corredores de seguros ha sido calificado como injusto en nuestra doctrina por Barrientos ${ }^{85}$, autor que sugiere, además, un reenvío a la ley alemana en esta materia (en adelante, vvg 2008).

Este reenvío debe entenderse en el contexto de la intervención de Osvaldo Contreras en la tramitación parlamentaria de la ley 20.667, quien presentó una serie de observaciones, comentarios y sugerencias de modificaciones al texto del Proyecto

81 Historia de la ley 19.301, 173, disponible en [www.bcn.cl/historiadelaley/nc/historia-de-la-ley/6941/].

82 Historia de la ley 19.301, 256, disponible en [www.bcn.cl/historiadelaley/nc/historia-de-la-ley/6941/].

83 Véanse Muñoz Paredes, J. M., Los corredores de seguros, Pamplona, Thomson, Civitas, 2. ${ }^{\text {a ed., }}$ 2012, 225 ss.; Peñas Moyano, Obligaciones..., cit., 595 ss.

84 Revisada la historia de la ley 20.667, constatamos lo siguiente: "Es de toda lógica que se extienda dicho sistema de responsabilidades al propio asegurador cuando el asegurado contrata directamente con él o con sus agentes de ventas. No tiene lógica que si el asegurado contrata por intermedio de un corredor esté legalmente protegido de los errores y omisiones incurridos en la contratación y en cambio no lo esté cuando contrata directamente con el asegurador". Véase Historia de la Ley 20.667, 96, disponible en [www.bcn.cl/historiadelaley/nc/historia-de-la-ley/4463/].

Barrientos, “Artículo 529...”, cit., 339. 
de Ley sobre Contrato de Seguro y a las indicaciones formuladas por el Supremo Gobierno (Superintendencia de Valores y Seguros), en concreto, y, para el caso del deber de información a cargo del asegurador, una referencia a la vVG 2008 ${ }^{[86]}$. La referida ley impone en el $\S 6$ un deber de asesoría a favor del asegurado y en el $\S 7$, un deber de información. El $\S 6$ dispone en términos generales una obligación de asesoramiento a cargo del asegurador, que debe ser documentada y por escrito, y comprende una calificación del seguro que de mejor manera se adapte a las necesidades del tomador y un consejo en este sentido. Por su parte, el $\S 7$ dispone la obligación del asegurador de entregar por escrito la información sobre el contenido -las condiciones- del contrato ofrecido.

Para nosotros, la novedad que introduce el legislador chileno queda representada, por un lado, en la extensión del ámbito subjetivo del deber de asesoramiento ${ }^{87}$ que incluiría además del corredor al asegurador, y por otro lado, en la forma de materialización de estos deberes, que debe ser por escrito, pues de esta manera lo recoge expresamente el legislador chileno en el artículo 514 inciso segundo, exigencia que debe extenderse al artículo 529 n. ${ }^{\circ} 1$ del c. co. y al artículo 57 del DFL 251 . Esto quedaría reforzado si consideramos la VVG como fuente del artículo 529 n. 1 del c. co., que impone en el $\S 6$, a propósito del deber de asesoramiento, una obligación que debe cumplir dos presupuestos: ser documentada y presentarse por escrito.

\section{Deber de asesoramiento en los artículos 57 del DFL 251 y 529 n. 1 del c. co. Coincidencias y divergencias}

Previo a la determinación de las coincidencias y divergencias del deber de asesoramiento en el contexto de los citados artículos 57 del DFL 251 y 529 n. ${ }^{\circ} 1$ del c. co. formulamos lo siguiente: dividiremos este deber de conducta en tres fases o dimensiones: consejo, examen de objetividad y advertencia.

\section{a. Deber de consejo}

Consejo, en un sentido amplio y de acuerdo con lo que dicta el Diccionario de la Real Academia Española, podría entenderse como una "opinión que se expresa para orientar una actuación de una determinada manera" 88 . Se trata de la simple o mera recomendación ${ }^{89}$. Pues bien, este deber de consejo, integrado al deber legal de asesoramiento en materia de seguros, va más allá. En este sentido, debemos entender que es un deber vinculado al profesionalismo que recae tanto en el asegurador como en

86 Historia de la Ley 20.667, 96, disponible en [www.bcn.cl/historiadelaley/nc/historia-de-la-ley/4463/].

87 Véase Peñas Moyano, Obligaciones..., ob. cit., 586 ss.

88 Véase FABre-Magnan, De l'obligation, cit., p. 9.

89 Sobre el significado de consejo en el ordenamiento jurídico chileno, véase por todos GoLDENBERG, Los contornos..., cit., 10 ss. 
el corredor de seguros, que tiene por objeto ilustrar o dar una explicación al contratante o asegurado sobre sus necesidades de cobertura, precisando en concreto el o los riesgos asegurados que pretende traspasar al asegurador y cuáles serían sus opciones. Es, sin duda, un deber de conducta que no obstante estar explicitado por medio del deber de asesoramiento, es asimismo una exigencia de la buena fe objetiva y tiene en este sentido un contenido subyacente o no explicitado por el legislador. Su correlato es el comportamiento leal y correcto para satisfacer de la mejor manera el interés del contratante del seguro.

En nuestra doctrina y sobre el deber de consejo en general, Goldenberg sostiene que consiste en "acompañar a la contraparte en la reflexión que resulta necesaria para la declaración de una voluntad afirmativa, de ser el caso, para el perfeccionamiento del contrato" 90 . En opinión de este autor el deber de consejo orienta sobre el contenido de la información recibida, eliminando la neutralidad del deber de información ${ }^{91}$. En nuestra opinión, el deber de consejo que pesa en el asegurador o corredor de seguros, según sea directa o no la comercialización, constituye un deber de comportamiento preparatorio que permite ir completando la exigencia de asesoría a favor del asegurado o contratante del seguro y, por último, la finalidad fundamental del deber de información en el sentido omnicomprensivo que hemos propuesto.

Por otra parte, la extensión o, dicho de otra manera, la intensidad del deber de consejo dependerá si el seguro ofrecido es de grandes riesgos o es un seguro ofrecido a un consumidor ${ }^{92}$. En el primer caso, se trata de un extremo en el que no resulta fácil o, quizás conveniente, fijar un estándar aplicable para todos los casos. Habrá supuestos en los que el consejo como instrumento de tutela no se justifique y otros en los que sí ${ }^{93}$. En el caso de los consumidores no hay duda, pues, como ya hemos señalado desde el inicio de nuestra exposición, en estos casos el nivel de ignorancia del profano le impide por sí solo reflexionar o deliberar sobre lo que es conveniente o no, según sus necesidades de protección.

\section{b. Examen de objetividad}

El examen de objetividad consiste en precisar o determinar las diversas condiciones que el mercado ofrece al tomador o asegurado en el contexto de sus necesidades de

90 Goldenberg, Los contornos..., cit., 15.

91 GoldenBerg, Los contornos..., cit., 16.

92 Goldenberg plantea que la intensidad del deber de consejo dependerá del nivel de ignorancia del sujeto que busca contratar. GoldenBerg, Los contornos..., cit., 16.

$93 \mathrm{Al}$ abordar los límites de l'obligation de conseil que pesa en el corredor de seguros, en el caso de los asegurados industriales o profesionales -grandes riesgos para nosotros-, Lambert-Faivre y Leveneur sostienen que esta obligación queda morigerada debido a la competencia técnica del contratante del seguro, que eventualmente puede ser superior a la del intermediador y del propio asegurador. Lambert-Faivre, Y. y Leveneur, L., Droit des Assurances, Paris, Dalloz, 2011, 127. Véase Latorre, Los deberes de..., cit., 224-225. 
amparo o protección, que deben basarse en el o los riesgos a los que está expuesto y cuyos efectos pretende traspasar al asegurador. Este examen de objetividad tiene una primera fase consistente en investigar los productos ofrecidos por el mercado de seguros, una segunda etapa de selección de aquellos productos que se ajustarían de mejor manera a las necesidades e intereses del contratante del asegurado y, finalmente, una tercera etapa de entrega de información sobre las condiciones seleccionadas ${ }^{94}$.

El resultado del examen de objetividad ${ }^{95}$ permitiría al tomador o asegurado comparar las distintas opciones, no solo en precio, sino también en condiciones de cobertura. Pues la posibilidad evaluar los términos del contrato con el objeto de determinar si estos se ajustan a los intereses de amparo que ofrece el seguro es tan esencial o relevante como el análisis económico del valor del contrato (la prima) ${ }^{96}$.

\section{c. Deber de advertencia}

Finalmente, encontramos el deber de advertencia, que consiste en informar al contratante del aseguro sobre las ventajas y desventajas de los productos seleccionados por el corredor de seguros en su examen de objetividad, o en el caso del asegurador simplemente reparar o prevenir sobre lo mismo: ventajas y desventajas de la oferta concreta de contratar $^{97}$.

Por su parte, Alonso Pérez analiza el deber de advertencia desde la perspectiva de los Principios Europeos de Derecho de los Contratos (artículo 1:103) y del Marco Común de Referencia (artículo 2:102). La autora concluye en primer término que son obligaciones o deberes precontractuales y luego sostiene que desde una perspectiva funcional y no obstante ubicarse el deber de advertencia en la fase de formación del contrato, no se equipara al deber de información, pues el deber de advertencia no tiene una finalidad preventiva frente a la problemática de la asimetría provocada por déficit de información ${ }^{98}$. Nos apartamos de la propuesta de Alonso Pérez, pues, como la misma autora sostiene, la funcionalidad apunta a obtener una decisión racional y libre, ajustada a los intereses de los contratantes ${ }^{99}$, que para el caso que nos interesa, el contrato de seguro, se trata de la prima y la cobertura.

94 Para Latorre, el análisis o examen de objetividad consiste en "haber estudiado un número suficiente de contratos de seguros, precisar luego las razones de la elección del corredor en atención a las necesidades e intereses del tomador". Latorre, Los deberes..., cit., 229.

95 Véase Latorre, N., "Independencia del corredor de seguros", en Bataller, J.; Quintáns, M. R. y VeIGA, A., La reforma del derecho de seguros, Pamplona, Aranzadi, 2015, 581.

96 Véase EcKARdt, M., "Insurance Intermediation, an Economic Analysis of the Information Services Market”, Germany, Physica-Verlag a Springer Company, 2007, 5.

97 Para Bataller, este deber consiste en "advertir sobre las inconsistencias en la cobertura de forma paralela al deber de información [...]". BATALLER, J., "Una mejor protección del asegurado es posible", en GiRgado, P. (dir.), El contrato de seguro y su distribución en la encrucijada, Pamplona, Aranzadi, $2018,367$.

98 Alonso Pérez 2012, La función..., cit., 31.

99 Alonso Pérez 2012, La función..., cit., 31. 


\section{d. Coincidencias y divergencias del deber de asesoramiento en el contexto de los artículos 57 del DFL 251 y $529 n .^{\circ} 1$ del c.co.}

De lo que hemos señalado, podemos formular que la obligación de asesoramiento que recae tanto en el corredor de seguros como en el asegurador ${ }^{100}$ debe entenderse en el sentido de aconsejar o ilustrar sobre el contenido del contrato de seguros y aclarar las materias que el contratante requiera para una adecuada comprensión del contenido contractual cuya información ha recibido previamente ${ }^{101}$, además de advertir sobre lo favorable y desfavorable de los productos de seguros ofrecidos ${ }^{102}$. De este modo, el contratante del seguro tendrá claridad de la cobertura y podrá elegir la opción que estima más apropiada a sus intereses, entendemos por ello cobertura y precio ${ }^{103}$.

No obstante lo señalado, este deber de asesoramiento tiene un matiz de contenido dependiendo del sujeto obligado a su cumplimiento: el asegurador o el corredor de seguros. Así, tratándose del examen de objetividad, pareciera que el legislador aumenta el nivel o intensidad de protección a favor del asegurado o tomador del seguro si es el corredor quien comercializa, pues están obligados a buscar alternativas en cobertura y precio en el mercado que se adapten mejor a las necesidades de cobertura que busca el asegurado o tomador. Este proceso de investigación y selección de condiciones de mercado se relaciona, finalmente, con el carácter independiente de este tipo intermediadores ${ }^{104}$.

Como podemos ver y, por razones de lógica, el deber de asesoramiento en cuanto al examen de objetividad no sería aplicable al asegurador que comercializa seguros de manera directa. El nivel de intensidad y protección en este caso quedaría en el plano de consejo y la advertencia, que ya hemos tratado.

100 Como sostiene Donati, se trata de una obligación que tiene por objeto una prestación de hacer (prestazione faciendi). Donati, A., Trattato del Diritto delle Assicurazioni Private, volume primo, Milán, Guiffrè, 1954, 514; GIRGADO, P., "Obligaciones de información del mediador de seguros", en Quintáns, M. R. (dir.), Estudios sobre mediación de seguros privado, Madrid, Thomson, 2013, 233.

101 Revisada la historia de la ley 18.814, el legislador entiende que "lo que justifica la actividad del corredor de seguros, es la naturaleza compleja del producto que ofrecen y la necesidad que informen completamente a los asegurados". En este sentido la historia de la ley 18.814, consultada en la Biblioteca del Congreso Nacional. En este supuesto, la doctrina extranjera sostiene que esta obligación de consejo complementa la obligación de información principal, es parte de esta y, busca suplir el nivel de ignorancia del contratante del seguro en asuntos técnicos y jurídicos. En este sentido, por todos, BeIGnier, B., Droit des Assurances, Toulluse, Montchrestein, 2011, 114-115. La doctrina española al analizar la directiva 2002/92/CE superpuesta en la ley 26/2006 en España, separa la obligación o deber de informar, de la obligación de asesoramiento. La obligación de asesorar consiste en proporcionar al contratante del seguro o tomador las mejores condiciones de cobertura que obtenga del mercado basado en un análisis objetivo de las mismas, y que se ajusten a las condiciones de cobertura que solicité el contratante. Por todos, GiRGADo, Obligaciones de..., cit., 253. Lo mismo ocurre y con mayor énfasis en la Directiva de la UE 2016/97.

102 BATALLER, Una mejor protección..., cit., 367.

103 Véase Quintáns, R., "Principales novedades de la ley 26/2006 de mediación de seguros privados y reaseguros", en Revista Española de Seguros, n. ${ }^{\circ}$ 127, $2006,548$.

104 Girgado, Obligaciones de..., cit., 235-236. 


\section{Conclusiones}

De lo que hemos señalado, una división funcional del deber de información, entendida desde la perspectiva de su incumplimiento y los efectos que acarrea, carecería de sentido, pues, cualquiera sea el deber de conducta incumplido, el efecto será el mismo: una alteración en el proceso de decisión racional de contratar, que desde la dimensión jurídica trastoca la formación del consentimiento y provoca una frustración en la satisfacción del interés de amparo del contratante del seguro.

De esta manera, podemos concluir que nuestro ordenamiento jurídico en los artículos 514, $529 \mathrm{n} .^{\circ} 1$ del c. co., artículo 57 del DFL 251 , artículos 9..$^{\circ}$ y $10 .^{\circ}$ del DS 1055 y NCG 420, impone un deber de información omnicomprensivo, cuya finalidad consiste en dejar al contratante del seguro en la mejor posición posible respecto del contenido contractual y su compresión.

Así, dentro de este deber de información en sentido lato podemos identificar un deber de suministro de datos y un deber asesoramiento, que coadyuva o complementa al primero con miras en la adecuada comprensión de los términos del seguro, en especial, cobertura y precio (prima). Por su parte, el deber de asesoría comprende consejo o ilustración sobre las condiciones del seguro, un examen de objetividad sobre condiciones del mercado y un deber de advertencia. Dejamos asentado que, existiendo dos sujetos obligados a cumplir el deber de información, asegurador y corredor de seguros, el primero queda fuera de la obligación de realizar un examen de objetividad. En este sentido, el nivel de intensidad es menor.

Para terminar, en nuestra opinión, y si bien el deber de suministro de datos y el deber de asesoramiento tienen una autonomía conceptual, son interdependientes funcionalmente, en un sentido finalista orientado a la determinación de su incumplimiento y los efectos derivados de su inejecución. Es, en consecuencia, un deber de información omnicomprensivo.

\section{Referencias}

Alonso Pérez, M. T., "La función de las obligaciones precontractuales de advertencia en la formación del contrato de servicios (estudio de derecho contractual europeo)", Indret Revista para el Análisis de Derecho, n. . 3, 2012, 1-34.

Barrientos, M., Daños y deberes en las tratativas preliminares de un contrato, Santiago, Legal Publishing, 2008.

BARRIENTOS, M., Normas sobre la protección de los derechos de los consumidores en el contrato de seguro en Chile, Madrid, Fundación Mapfre, 2012.

BARRIENTOS, M., "Nuevos deberes precontractuales de información en los certificados de cobertura provisorio, definitivo y la propuesta del contrato de seguro", en Revista de Derecho Universidad Católica del Norte, n. ${ }^{\circ}$ 1, 2015, 65-104. 
Barrientos, M., Artículo 529 n. ${ }^{\circ}$ 1, "Obligaciones del asegurador (el deber precontractual de información)”, en Ríos, R. (dir.), El contrato de seguro. Comentarios al título viI Libro II del Código de Comercio, Santiago, Thomson, 2015, 334-360.

Barros, E. y Rioseco, A., "Responsabilidad de quien da un mal consejo", en VIDAL A., y otros (dirs.), Estudios de Derecho Civil x. Jornadas Nacionales de derecho Civil, Santiago, Thomson-Reuters, 2015, 633-651.

Bataller, J. y Seguí-MAs, E., "La distribución como factor determinante en la protección del asegurado”, Quintáns, M. R.(dir.), Estudios sobre mediación de seguros privados, Pamplona, Aranzadi, 2013, 119-159.

BAtAller, J., "Una mejor protección del asegurado es posible”, en Girgado, P. (dir.), El contrato de seguro y su distribución en la encrucijada, Pamplona, Aranzadi, 2018, 347-372.

BATAller, J., "Integración horizontal en la distribución de seguros privados”, BATALLER, J. y Quintáns, M. R., Distribución de seguros privados, Madrid, Marcial Pons, 2019, 737-752.

Beckmann, R., Versicherungsrechts-Handbuch, München, Verlag C. H. Beck, 2011.

BeIGNIER, B., Droit des Assurances, Toulluse, Montchrestein, 2011.

BeDnARZ, Z., "Breach of information duties in the B2C e-commerce: adequacy of available remedies", Revista D'internet, Dret I Politica, n. . 22, 2016, 1-18.

Contreras, O., Derecho de Seguros, 2. . ed., Santiago, Thomson-Reuters, 2014.

Contreras, O., "Estatuto legal de los corredores de comercio en general, de los corredores de seguro en particular y prescripción de su responsabilidad", en EsCOBAR, M. (ed.), Estudios de Derecho Comercial. Séptimas Jornadas Chilenas de Derecho Comercial 2016, 2017, 491-515.

De la MaZa, I., "El suministro de información como técnica de protección de los consumidores: los deberes precontractuales de información", Revista de Derecho Universidad Católica del Norte, año 17, n. ${ }^{\circ}$ 2, 2010, 21-52.

De la MaZA, I., Los límites del deber precontractual de información, Pamplona, Aranzadi, 2010. 
De LoRenzi, V., "Contratto di assicurazione e dichiarazioni inesatte e reticenti sul rischio dell'assicurato", en Assicurazioni, Rivista de Diritto, Economia e Finanza delle Assicurazzioni private, n. ${ }^{\circ}$ 2, 2014, 195-219.

De los Mozos, J. L., El principio de buena fe. Aplicaciones prácticas en el derecho español, Barcelona, Bosch, 1965.

Donati, A., Trattato del Diritto delle Assicurazioni Private, volume primo, Milán, Editore Giuffrè, 1954.

ECKARDT, M., "Insurance Intermediation, an Economic Analysis of the Information Services Market”, Germany, Physica-Verlag a Springer Company, 2007.

Fabre-Magnan, M., De l'obligation d'information dans les contrats, Paris, Libraire Général de Droit et de Jurisprudence, 1992.

Gallo, P., "Contratto e buona fede: buona fede in senso oggettivo e trasformazioni del contratto", Milán, Utet Giuridica, 2014.

Girgado, P., "Obligaciones de información del mediador de seguros”, en Quintáns, M. R. (dir.), Estudios sobre mediación de seguros privado, Madrid, ThomsonReuters, 2013, 231-258.

Goldenberg, J. L., "Los contornos del deber de consejo como expresión de la colaboración y como técnica de protección”, en Revista de Derecho Universidad de Concepción, n. $244,2018,12-41$.

Gómez Calle, E., Los deberes precontractuales de información, Madrid, La ley, 1994.

Hinestrosa, F., "El deber de sinceridad del tomador del seguro en su declaración del estado del riesgo", en Revista Iberolatinoamericana de Seguros, n. 27, 2007, 121-148.

Khoury, H., L'information et le conseil dus au preneur d'assurances, Marseille, Presses Universitaires D’Aix-Marseille, 2011.

LANDINI, S., "Sanzioni amministrative e trasparenza nei rapporti assicurativi. Pubblico e privato nei mercati regolamentati", en Assicurazioni, Rivista de Diritto, Economia e Finanza delle Assicurazzioni private, n. ${ }^{\circ}$ 3, 2014, 411-425.

Lambert-Faivre, Y. y Leveneur, L., Droit des Assurances, Paris, Dalloz, 2011. 
Latorre, N., "Los deberes de información y asesoramiento del mediador de seguros", en Cuñat, V. y Bataller, J. (dirs.), Comentarios a la ley de mediación de seguros y reaseguros privados, Pamplona, Thomson Civitas, 2007, 221-239.

LÓPEZ, P., "La tutela precontractual en la ley 19.496: su configuración, alcance y eventual convergencia con aquella propia de la contratación civil", en Revista Chilena de Derecho, 2019, vol. 46, n. . 2, 399-425.

LÓPEZ, P., "El principio de equilibrio contractual, en el código civil chileno y su particular importancia como fundamento de algunas instituciones del moderno derecho de las obligaciones en la dogmática nacional", Revista Chilena de Derecho Privado, n. ${ }^{\circ}$ 25, 2015, 115-181.

Llobet, J., El deber de información en la formación de los contratos, Madrid, Marcial Pons, 1996.

MacDonald, P., "The fair presentation of commercial risks under the insurance act 2015”, en Clarke, M. y Soyer, B. (eds.), The Insurance Act 2015, A New Regimen for Commercial and Marine Insurance Law, New York, Routledge, 2017, 12-36.

Mas BAdíA, M. D., "El contrato de electrónico de seguro: formación del contrato y tutela del usuario", Revista Aranzadi de Derecho y Nuevas Tecnologías, n. ${ }^{\circ}$ 38, 2015, 63-102.

Monsalve, V., "Consideraciones actuales sobre la obligación precontractual de información, una perspectiva europea”, Revista Vniversitas, n. ${ }^{\circ}$ 117, 2008, 115-152.

Muñoz Paredes, M. L., El deber de declaración del riesgo en el seguro, Pamplona, Aranzadi, 2018.

Muñoz Paredes, J. M., Los corredores de seguros, Pamplona, Thomson Civitas, 2. ed., 2012.

Musy, A., "Il Dovere de informazione", Trento, Università degli Studi di Trento, 1999.

Nasser, M., Seguros de Personas, Santiago, Thomson-Reuters, 2018.

Peñas Moyano, M. J., “Obligaciones generales de información”, en Bataller, J. y Quintáns, M. R.(dirs.), Distribución de seguros privados, Madrid, Marcial Pons, 2019, 581-606. 
Peñas Moyano, M. J., "Conductas de mercado", en Bataller, J. y Peñas Moyano, M. J. (dirs.), III Congreso Nacional de Ordenación, Solvencia y Supervisión en Seguros Privados, Valencia, Low Cost Books, 2016, 503-529.

Peñas Moyano, M. J., "Relaciones entre la normativa contractual y de supervisión para la protección del asegurado: el deber de información previa al tomador del seguro", en Cuñat, V. y Bataller, J. (dirs.), Supervisión de seguros privados, hacia solvencia II, Valencia, Tirant lo Blanch, 2013, 669-695.

Pinochet, R., “Artículo 12A”, en De la MAza, I. y Pizarro, C. (dirs.), La protección de los derechos de los consumidores, 1. a ed., 2013, 265-282.

PIRILli, D., "La fase precontrattuale nell' assicurazione", Assicurazioni, Rivista de Diritto, Economia e Finanza delle Assicurazzioni private, n. ${ }^{\circ}$ 3, 2013, 417-434.

Quintáns, M. R., "Información y conflicto de intereses en la comercialización de seguros", en Girgado, P. (dir.), El contrato de seguro y su distribución en la encrucijada, Pamplona, Aranzadi, 2018, 193-236.

Quintáns, R., "Principales novedades de la ley 26/2006 de mediación de seguros privados y reaseguros", en Revista Española de Seguros, n. ${ }^{\circ}$ 127, 2006, 548.

Ríos, R., “Capítulo introductorio””, en El contrato de seguro. Comentarios al título VIII Libro II del Código de Comercio, Santiago, Thomson-Reuters, 2015, 31-41.

Ríos, R., "La obligación del asesoramiento a cargo del corredor en la fase de formación del seguro como contrato de consumo", en Escobar, M. (ed.), Estudios de Derecho Comercial, Séptimas Jornadas Chilenas de Derecho Comercial 2016, 2017, 519-529.

Ríos, R., El deber precontractual de declaración del riesgo en el seguro de daños, Santiago, Thomson-Reuters, 2014.

Simon, H. A., Reason in Human Affair, California, Stanford University, 1983, 12 y ss.

SÁnchez SAntos, J. M., "Estructura del mercado y competencia en la distribución de seguros: una perspectiva económica”, en Quintáns M. R. (dir.), Estudios sobre mediación de seguros privados, Pamplona, Aranzadi, 2013, 29-56.

SÁnchez Santos, J. M., "El mercado de la Distribución de Seguros en España: bases para al análisis económico de su regulación”, en BATALLER, J. y QuintÁns, M. R. (dirs.), Distribución de seguros privados, Madrid, Marcial Pons, 2019, 13-34. 
Tirado Suarez, F. y SARTi, M. A., Ley de mediación en seguros y reaseguros privados, Santiago, Thomson-Aranzadi, 2007.

VeIGA, A., Condiciones en el contrato de seguro, 2. ${ }^{\text {a }}$ ed., Granada, Comares, 2008.

Zimmermann, R., El nuevo derecho alemán de las obligaciones, Barcelona, Bosch, 2008. 